\title{
Translation of kinship terms from Chinese into English from the perspective of relevance theory
}

\begin{abstract}
Because of the differences between Chinese and English kinship systems, the connotation and the usage of Chinese and English kinship terms are quite different. Relatively speaking, Chinese kinship terms are more complex than the English ones and have more socialized usage. When doing the translation the translator should first deal with the codes according to the source text writer's intention and target text reader's cognitive environment and enable the target text readers to find the optimal relevance between the translated text and the context. The translator should first get a true understanding of the contextual effect of the source text according to the inference on the ostensive behavior of the source text writer and try to transfer the original intention of the author to the target reader and give them conveniences to make the right assumptions. As to the translation of kinship terms, the translator should first find out the intention of the author to use the term and meanwhile think about the ability of acceptance of the target reader. By considering the entire relevant elements, the translator should find the optimal relevant term.
\end{abstract}

Keywords: relevance theory, kinship terms, cultural default, translation equivalence
Volume 2 Issue 2 - 2018

\author{
Jiying Chen, Chuanmao Tian \\ Yangtze University, China
}

Correspondence: Chuanmao Tian, Yangtze University, China, Email tcm_316@163.com

Received: December 29, 2017 | Published: April 06, 2018

\section{Introduction}

When people are involved in the communication process, they do more than just to understand the speaker's thoughts and feelings. People are using language in subtle ways to define their relationship to each other, to identify themselves as part of a social group and to establish the kind of speech event they are in, which we call the second function of language. This second function is clearly highlighted in terms of address, which is defined by Ralph fasold" as "the words speakers use to designate the person they are talking to while they are talking to them." as an important part of the address terms; kinship terms share the same function. Both the Chinese and English languages contain a great number of kinship terms. However, because of the difference of cultural background between Chinese, English, and the connotation and the usage of kinship terms in the source language do not necessarily coincide with those in the target language, thus forming the cultural default in the translation of kinship terms.

Many scholars have spared no effort to solve this problem. The scientific study of kinship terms began with the publication of the Lewis Henry Morgan's system of consanguinity and affinity of the human family, published in 1871. Morgan has amassed a huge amount of data on kinship terminology to work out a classification of kinship systems. Morgan has assumed that human society has evolved through a series of stages from primitive savagery to civilization, and he sees kinship terminologies as reflecting these stages. Primitive promiscuity, for example, is signaled by a Hawaiian type of kinship nomenclature. Morgan has made two major distinctions between classificatory kinship terms: terms, which subsume a relatively large number of biological kin types and Descriptive terms, which subsume a relatively small number of types, preferably having unique referents. He has imposed this scheme on whole terminological systems. He has then fitted the typological scheme to his evolutionary framework, where he points out those primitive systems are classificatory, whereas civilized systems are descriptive. He has ignored the problem of how to analyze degrees of extension, and how to discover the semantic criteria by which people make distinctions between kindred terms and later in 1929, Kroeber suggested eight categories: generation, affinity, collaterality, gender of relative, bifurcation, relative age, gender of the speaker and decadence. He has examined these differences to distinguish kinship terms. This kind of distinction is important because it first destroys the notion of a simple classification of kinship terminologies and suggests a way of dealing with the mass of kinship terms, groups from different The study of kinship terms in china can be dated back to the year when shiqin of ER YA, (The Ljubljana comment pro, interpretation of kinship terms of the standard ancient Chinese dictionary) was finished and the famous scholar liang zhangju gave a general description of the ancient Chinese kinship terms in his great work the collection of kinship terms (1992). In modem times, scholars like zhao yuanren, lu shuxiang and jiang lansheng have made detailed studies of the kinship term systems (Table 1).

As for the translation of kinship terms, many scholars have analyzed this phenomenon under the framework of culture and functionalism. Professor Bao Huinan ${ }^{2}$ devotes one chapter to the translation of kinship terms in his work cultural context and linguistic translation (2001), in which he has studied the differences between Chinese and English kinship terms and explained some strategies in translation. Others have tackled the translation of kinship terms according to their functions. These theories have solved certain problems in the translation of kinship terms to some extent for instance, we should omit the kinship terms when translating them into another language and we should make conversions if the literal translation causes failures in Communication.

These former studies of the translation of kinship terms are quite fruitful. It gives a new perspective to translation because in the last forty years, most of the studies of kinship terms are static and descriptive and few of them are dynamic ones. Functionalism focuses on pragmatic studies and pragmatic features of kinship terms and 
puts more emphasis on communication. It can solve many problems caused by cultural differences. However, some scholars criticize that translation from the perspective of functionalism sometimes goes to another extreme when they just pursue the equivalence of function and ignore the art of language.

As a theory based on communication, relevance theory (RT) prefers to consider all the relevant elements in translation and find the most suitable words or expressions, it tends to reach a kind of balance. Therefore, relevance theory can explain the phenomenon of translation macroscopically. This thesis will try to prove that relevance theory can give a new approach to the translation of kinship terms in the following chapters.

Table I A comparison of major Chinese and English kinship terms

\begin{tabular}{|c|c|c|c|c|c|}
\hline Chinese & Relationship & English & Chinese & Relationship & English \\
\hline A grandmother & Father's mother & Grandmother & Aunt & Sister of one's father & My aunt \\
\hline Grandmother & Mother's mother & Grandmother & Aunt & Sister of one's mother & My aunt \\
\hline Grandpapa & Father's father & Grandfather & Aunt & Brother of one's mother & My aunt \\
\hline Grandpa & Mother's farther & Grandfather & Aunt. & $\begin{array}{l}\text { Wife of the brother of } \\
\text { one's father }\end{array}$ & My aunt \\
\hline Dad & Father & Father & My brother & Elder brother & Brother \\
\hline My mother & Mother & Mother & My brother & Younger brother & Brother \\
\hline Uncle & Father's elder brother & Uncle & Sister & Elder sister. & Sister. \\
\hline Uncle & Father's younger brother & Uncle & Sister & Younger sister. & Sister. \\
\hline My uncle & Mother's brother & Uncle & Sister/brother & $\begin{array}{l}\text { Elder/younger sister's } \\
\text { husband }\end{array}$ & Brother-in-law \\
\hline Your Parent & $\begin{array}{l}\text { Husband of the sister of } \\
\text { one's father }\end{array}$ & Uncle & Brother Law & $\begin{array}{l}\text { Younger brother's } \\
\text { husband }\end{array}$ & Sister-in-law \\
\hline In the Fu & $\begin{array}{l}\text { Husband of the sister of } \\
\text { one's mother }\end{array}$ & Uncle & Sister. & Elder brother's husband & Sister-in-law \\
\hline Niece & $\begin{array}{l}\text { Daughter of one's } \\
\text { brother }\end{array}$ & Niece & My nephew & Son of one's brother & Nephew \\
\hline The nephew & $\begin{array}{l}\text { Daughter or son of one's } \\
\text { sister. }\end{array}$ & Niece/nephew & Daughter & Daughter & Daughter \\
\hline
\end{tabular}

\section{Objective of the research}

This thesis will investigate the translation of kinship terms as a whole system from the perspective of RT, which was proposed by Dan Sperber \& Deirdre Wilson ${ }^{3}$ in their communication and cognition relevance: (2001). RT has opened new perspectives for the research of modern pragmatics and modem communication theories and it has a great influence on many other research areas including cognitive science, philosophy and linguistics, language translation studies. Moreover, it provides a unified theoretical framework for translation. In this thesis, a group of Chinese kinship terms and their English versions will be applied the purpose of using them is to explain what kind of strategy should be used in a dynamic context and in what The sense a translation can be regarded as faithful from the perspective of RT. This paper will also testify that the RT subsumes the more inclusive explanations of the translation phenomenon in kinship terms.

\section{Significance and necessity of the research}

The study of the translation of kinship terms from the perspective of the RT is of both theoretical and practical significance. As for
RT, since the day it first appeared in the publication of relevance: communication and cognition in 1986, it has received both praise and criticism. Although some scholars say that it lacks scientific methods, it still gives a new perspective for translation because it regards translation as a dynamic process. The study of the translation of the kinship terms also has practical significances. Kinship terms are a part of the address terms. Nowadays, address terms have formed a complete system although the scholars in linguistics are now of different opinions as to whether the Chinese lexical words of address form an independent system. The study of kinship terms can help to make clear the inner relationship of kinship terms which have a close relationship with the comprehension of a context. It can also help us to explore the dynamic contact between culture, profession, age and other social elements. Using kinship terms is an important social behavior and it is necessary for us to use the proper type of kinship terms in proper situations whether the communication happens within a culture or cross-culturally.

\section{Literature review}

There are some research achievements on Chinese and English kinship terms as well as their translation. 


\section{Previous studies on kinship terms}

The way we address people is a matter of great importance in most cultures. The addressing terms are the ones used to show the relationships between people or to distinguish their identity, social status and career. Ralph fasold1 defines the address the terms in the sociolinguistics of language as "the words speakers use to designate the person they are talking to while they are talking to them. According to Li Jiayuan4, appellations are words that people have acquired owing to their kinship and other relationships and not all appellations can be used as address terms. Face-to-face appellations are generally divided into kinship and non-kinship appellations. Most appellations arc comparatively stable but they do change slowly with the passage of time and vary with the speakers' geographical positions, ages and status. Chinese and English kinship appellations are similar in their basic terms, but the Chinese make much clearer distinctions in the above-mentioned aspects. Moreover, many Chinese kinship appellations can be extended to address non-relatives, which is rare in English. ${ }^{4}$

According to Zhang Aiqun5, address terms are all indispensable part of people's daily life and literary works. Languages, owning to different cultural backgrounds and social structures, there are pronounced distinctions between English and Chinese address terms. Chinese address terms are descriptive. They can indicate the addressee's gender, age and consanguinity clearly. The address terms in English are classificatory. They are general. Kinship is one of the complex systems of culture. All human groups have a kinship terminology which is defined as a set of terms used to refer to kin. Kinship can have an influence on many fields in our life. ${ }^{4}$

\section{Previous studies on the translation of kinship terms}

Translation is an activity involving usually two languages and two national cultures. Conditioned by the strikingly multiplied dimensions of the worldwide cultural exchanges in recent years, the focus of contemporary translation studies has gradually shifted to the culture-related contemplation on translation practice. So the cultural translations are given more attentions now ${ }^{5}$.

According to Li Jiayuan4, only in taking cultural differences into account and adopting a comprehensive view toward translation activities can a translator avoid making mistakes and achieve successful communication when translating appellations as a cultural mediator who spans two languages and two cultures 4 and in the opinion of another translator Zhai Ying, ${ }^{6}$ English and Chinese languages are different not only at the linguistic level but also at the cultural level. Without the awareness, translators give liable to fall into the "cultural traps in translation. Zhai ${ }^{6}$ therefore, translators and translation researchers should pay enough attention to the effective transmission of Chinese cultural values.

\section{Application of relevance theory to translation}

According to Zhang Aiqun, ${ }^{5}$ relevance theory is the most influential pragmatic theory in western countries these years. The key point of the relevance theory is cognition and communication. It focuses on the effect that the cognitive context has on the inference of the communicator's communication intention. It claims that the nature of the communication is ostensive-inferential process. In relevance theory context is a set of psychological constructs, a subset of the reader's assumptions about the world. Context is not given but chosen.
In the process of the reader's inference, the reader chooses those more manifest or accessible contexts.

Relevance theory considers the translation as an ostensiveinferential process. It explains the intention of the author and the cognitive environment of the target reader and the strategy taken by the translator reasonably. Translation is regarded as an inter lingual communication which includes two rounds of communications. The translator connected the source writer and the target reader by acting as both the communicator and the audience. In the first random, a translator functioned as the audience. He tries to get the right intention of the source writer. In the second random, he acts as the communicator who interpreted the source writer's intention to the target reader through proper translations. ${ }^{5}$

According to $\mathrm{Wu}$ Xingmei, ${ }^{7}$ while evaluating the translation of an address term, no matter what kind of term it is, we should see whether it communicates the intention of the original term and whether it costs unnecessary processing effort. While translating an address term, a translator is supposed to make the intention of the source writer to meet the expectation of the target readers. He firmly recognizes the source writer's intention of the use of the term, assess the cognitive context and the expectation of the target reader, and finally express his interpretation of the source writer's intention in appropriate translation which should not take unnecessary processing effort $\mathrm{Wu}$.?

Kinship terms are a part of the address terms. Nowadays, address terms have formed a complete system although the scholars in linguistics are now of different opinions as to whether the Chinese lexical words of address form an independent system. The study of kinship terms can help to make clear the inner relationship of kinship terms which have a close relationship with the comprehension of a context. It can also help us to explore the dynamic contact between culture, profession, age and other social elements. Using kinship terms is an important social behavior and it is necessary for us to use the proper type of kinship terms in proper situations whether the communication happens within a culture or Cross-culturally.

The research of the translation of kinship terms has long been paid attention to by scholars from home and abroad. Relevance theory is the most influential pragmatic theory in the western world these years. The key point of RT is cognition and communication. It focuses on the effect that the cognitive context has on the inference of the communicator's communication intention. It considers translation as an ostensive-inferential process and reasonably explains the questions such as the intention of the author, the cognitive environment of the target reader and the strategy taken by the translator. It can explain the translation phenomenon in a macro-level view.

\section{An overview of kinship terms}

As has been mentioned in the previous chapter, the study of kinship terms is important to the study of cross-cultural communication and translation. However, up to now, the efforts made in the translation of kinship terms are quite limited. Before a theoretical study of the translation of kinship terms, we will first give a definition of kinship terms.

\section{Definition of kinship term}

The way we address people is a matter of great importance in most cultures. The addressing terms are the ones used to show the relationships between people or to distinguish their identity, 
social status and career. Ralph Fasold ${ }^{1}$ defines address terms in the sociolinguistics of language as "the words speakers use to designate the person they are talking to while they are talking to them. In most languages, there are two main kinds of address terms: names and second-person pronouns." Fasold ${ }^{1}$ kinship is one of the complex systems of culture. All human groups have a kinship terminology which is defined as a set of terms used to refer to kin. Kinship can have an influence on many fields in our life. For example, in most societies, kinships influence the things such as a which one calls and whom cannot marry, for whom one must show respect, whom one can joke with, and whom one can count on in a crisis. Kinship terms reflect the implied cultural connotation profoundly. The research on kinship terms shows that there are great differences existing between different cultures, especially between western culture and Chinese culture.

\section{Kinship terminology}

Kinship terminology refers to the words used in a specific culture to describe a specific system of familial relationships. They include the address terms used in different languages or communities for different relatives and the terms of reference used to identify the relationship of these relatives to ego or to each other. In the introduction part we have mentioned that Morgan $^{8}$ has made two major distinctions between kinds of kinship classificatory terms: terms, which subsume a relatively large number of biological kin types and descriptive terms, which subsume a relatively small number of types and the Chinese kinship terms, belong to descriptive terms while the Chinese kinship terms belong to classificatory terms.

As a system, the English kinship terminology mainly contains the following principal terms:

i. Mother, father, son, daughter, brother, sister.

ii. Uncle, aunt, nephew, niece

iii. Cousin (differently elaborated in different English speaking cultures)

iv. Grandfather, grandmother, grandson, granddaughter

v. Granduncle, grandaunt, grandniece, grandnephew (in many dialects)

vi. Great-grandmother, great-great-grandmother, great-grandfather, great-great-grandfather, and so on; and so on

vii. There are also the affinal terms: wife, husband, brother-in-law, sister-in-law, mother-in-law and father-in-law as well as uncle and aunt. On the other hand, he Chinese kinship terminology is a more complex system which we will discuss in detail in the following part.

\section{Characteristics of Chinese kinship terminology}

Before discussing the characteristics of Chinese kinship terminology, we must give a clear comparison between the major kinship terms in Chinese and English.

From Table 1, we can clearly see that the Chinese terminology tends to be much more complex than their English counterpart. Chinese kinship terminology represents a kind of family-centered social relationship. In Chinese culture, the family is so important that there is a highly elaborate system of kinship terms to describe the relationship between the family members and the relatives. In ancient times, family members encountered each other frequently in daily life in China therefore they had to have precise kinship terms to identify their identity. The Chinese kinship terms are a kind of descriptive terms with various forms and categories. In the process of history, it has evolved into a rigorous addressing system. The modem kinship terms have mainly inherited the nature of the old types which may have the following characteristics.

\section{The seniority in the family and the clan}

Traditionally, the Chinese kinship terminology has precise kinship terms to describe different generations, which not only reflect different generations but also the seniority of the same generation.

The Chinese kinship terminology has a strict hierarchy. The elder members of a family such as uncles and aunts grandparents, parents, can generally call family members of the younger generation by their first names, but not vise versa. This kind of phenomenon is also reflected in the age difference. The elder one of the brothers or sisters can directly call the first name of the younger ones but it is impolite for the younger ones to do so.

And among the same generation, the Chinese kinship terms also have special words to describe the different ranks. For example, one's three elder sisters must be addressed as Dajie (Mademoiselle, elder sister), Erjie (二, second elder sister), and Sanjie (Third Sister Liu, the third elder sister). And the three younger sisters must be addressed as Damei (big sister, the eldest younger sister), Ermei (2-mei, the second eldest younger sister), Sanmei (3-Mei, the third eldest younger sister) or one can call the names of the younger sisters directly in face-to-face talks. However, in English kinship terms, no expressions such as the first elder sister (dajie), the second elder Sisterrjie (e) and the first younger sister (Damei) actually exist in face-to-face talks. The English people prefer to call the names of a person directly. The following example can clearly show this kind of difference:

"Laosan, please open the door quickly." It is the voice of his third uncle Keming.

"Cheuh-hui, open the door!" It is his third uncle.

Family: 65 , by Ba Jin, ${ }^{9}$ trans by Yang Xianyi \& Gladys Yang ${ }^{10}$

\section{Gender differentiations in kinship terms}

Most of the Chinese kinship terms can denote the sex of the person we are talking to but some cannot. For example, the term "foreign" (Wai Shen nephew, nephew) corresponds to both niece and nephew in English. The reason is that the matrilineal relationship in England is more important than the matrilineal relationship in China; some of the Chinese kinship terms also do not convey differentiations. sex, for example, the English kinship term "cousin" can express Biaoge (cousin, the elder male cousin), Biaodi (cousin, younger male cousin), Biaojie (cousin, the elder female cousin), Biaomei (cousin, younger female therefore, cousin), and so on in the English-to-Chinese or the Chinese-to-English translation, we should find The precise connotation of the kinship terms and give the original term an equivalent rendering.

\section{Blood ties in kinship terms}

The Chinese have experienced a long time of matrilineal society in which the mother's family plays a key rule. Therefore, the kinship 
terms are the reflections of this tradition. For example, there are mainly two kinds of kinship terms in Chinese: one is the relation by consanguinity and the other is the relation by marriage. For example, a mother's brother and a father's brother have different terms. However, in, English, those kinds of relationship are not distinguished. For example:

My grandfather is his cousin, so he is kith and kin to me somehow, if you can make that out, I can't

My grandfather and his cousins or cousins, so he and I have relatives, you may be able to make this clear, I have no way to find out this relationship. ${ }^{11}$

Here, the intention of the original author is to make clear the exact relationship between the grandfather and another person. The expression "cousin" shows that it is a kind of relationship between relatives. In, English, there are no sub-terms to express "cousin". So the author uses the expression "kith and kin" to show that they belong to different kinds of cousin. However, in Chinese, we do classify "cousin" into two kinds according to the relation by consanguinity and relation by marriage. So it is quite proper to use "Cousin" (Biao Xiong Di, male cousins on the maternal side) and "Cousin" (Tang Xiong Di, male cousins on the paternal side) in Chinese to show the difference of blood relationship.

\section{Relevance theory and translation}

Many theorists and scholars have spared no pains to find out how human beings communicate with each other, which is also the essence of communication. As a theory based on communication and cognition, relevance theory will be introduced in this chapter and some of the basic concepts in relevance theory will be introduced as well.

\section{Relevance theory}

RT mainly concerns the communication between languages, with communication and cognition as its key points. It is neither rule-based nor maxim-based but takes the following point as its principle. The content, context and various implications of an utterance may raise different comprehensions in the hearer, and not all the assumptions available from the potential context are equally accessible at any given point in time. As a result, the hearer will use a single and universal standard to comprehend the utterance and this standard is sufficient to confirm the hearer a single way of comprehension. This standard is what we call relevance in relevance theory $\mathrm{He} \&$ Ran. ${ }^{12}$

According to Sperber \& Wilson ${ }^{13}$ the crucial mental faculty that enables human beings to communicate with one another is the ability to draw inferences from people's behavior. Rt argues that people make cognitive assumptions to interpret new information, the process of which automatically accords with the principle of relevance words, in other people are inclined to combine new information with the interrelated background knowledge in their cognitive environment to interpret utterances so as to get to know the world. It is a universal goal in communication that the recipient is ready to acquire relevant information and the communicator tries to make his utterance as relevant as possible. In this light, the principle of relevance, by integrating verbal communication with the relative cognitive environment, gives us some valuable insights into utterance comprehension in human communication and some explanations to the general laws involved in knowledge acquisition. Sperber \& Wilson. $^{14}$

\section{Cognitive context}

The former pragmatics mainly considers context as a variety of visual and concrete factors in the external environment of communication, however, RT defines the context of an utterance to be "the set of premises used in "interpreting an utterance". Sperber \& Wilson ${ }^{13}$ it is "a psychological construct, a subset of the hearer's assumption about the world". (ibid. definition (15) hence in this context in the relevance-theory framework refers to part of the hearer's "mental representation of the world", or the so-called "cognitive environment". In RT, context does not refer to some part of the external environment of the communication partners, be it the text preceding or following an utterance, situational circumstances, cultural factors and so on it rather refers to part of their "assumption about the world" Gutt. ${ }^{15}$

The cognitive environment of a person comprises a potentially huge amount of varied (ibid.: 27 for information. It not only includes the information in the physical environment but also the information that can be retrieved from the memory which may comprise information derived from preceding utterances plus any cultural or other knowledge stored there. However, any of the above information could serve as the potential context of an utterance, and the main question for successful communication is: "How do hearers manage to select the actual, speaker-intended assumptions from among all the assumptions they could use from their cognitive environment?" (Ibid. 28)

In chapter III of relevance: communication and cognition, sperber argues that relevance can be characterized in terms of the contextual effect." contextual effect is the relationship between the words and the context, the combination of the new information contained in the words and the old information. Sperber \& Wilson ${ }^{14}$ meanwhile, Sperber \& Wilson ${ }^{14}$ define relevance by saying "an assumption is relevant in a context if and only if it has some contextual effect in that context" and in Gutt's theory context modifications are referred to as contextual effects. The notion of a contextual effect is essential to a description of the comprehension process. Sperber \& Wilson ${ }^{14}$ the context assumptions can produce contextual effect in three ways:

1. The combination of the new information and the old information produces new contextual implication.

2. The new information emphasizes the present context assumptions.

3. The new information is contradictive to the present context assumptions and excludes the present context assumptions.

\section{Intention}

Sperber \& Wilson ${ }^{14}$ have a discussion of mutual knowledge assumption, cognitive environment and mutual manifestness. (ibid. 57) mutual knowledge means that the human beings should make clear the contextual information to each other with the change of the content in communication. However, it is hard to be achieved in real situations. Therefore, Sperber \& Wilson ${ }^{14}$ have suggested using the mutual manifestness" instead of "mutual knowledge." (ibid. 59) they explain that the cognitive environment" is the collection of a set of facts and assumptions people know and the mutual manifestness" is those facts and assumptions. The manifestness of cognitive environments is the key element of a successful communication. As has been proposed by Sperber \& Wilson, ${ }^{14}$ communication is an ostensive-inferential process. In light 
of the speaker, an ostensive communication is the process in which the intention is conveyed. Sperber \& Wilson ${ }^{14}$ compare the code model and the inferential model, and meanwhile they analyze the major problems in Grice's theory of communication.

RT does not discard the code model, and on the contrary, they regard encoding and decoding as the basis of the inferential model. The pragmatic rule is just all extension of the grammatical rule. All in all, Sperber $\&$ Wilson ${ }^{14}$ look on communication as a cognitive activity Gutt. ${ }^{15}$

Now, after making that statement clear, let's take a look at an important concept in relevance theory: intention.

Overt communication involves both informative and communicative intentions. The informative intention is the intention to inform the audience of something and the communicative intention is the intention to inform the audience of one's informative intention. Wilson people used to consider the purpose of translation as the transformation of meaning but it could not solve the pragmatic problems involved in translation. In reality, the transformation involves not only the meaning, but also the intention. From the perspective of RT, the translator should transfer the informative intention of the source text as well as the communicative intention to make sure the success of communication. However, it is a quite idealized state. When the two terms of address are not equivalent to each other, the communicative intention is usually preferred because it is more important. For example:

Yuchun said, "Later on, I knew that the thatched pavilion had been burnt. I was deeply worried about it. Now I am very glad to meet you. I admire that you are morally advanced. But I am so foolish and stupid, which is the reason why I am in a low position today."

Yu-Tsun replied: later I was very worried to hear that your temple had been burned down, now that I air lucky enough to meet you again, I am sure your virtue must be even greater. As for me, owing to my own inveterate folly, I have now been reduced to this." (A dream of the red chamber by the Cao Xueqin, et al. ${ }^{10}$ )

The Chinese people used to have the habit of using humble words to address them, which is reflected in the address Chang terms. (MA117) in china, using humble words is considered as a virtue. The number of self-addressing terms is large and the usage is complex. They can indicate status, gender, identity and profession. In this example, the information the term "cowardly" Bi Ren shows to the Chinese people is that the speaker uses this term to call himself and the speaker is polite to the hearer. However, western cultures do not consider using humble words as a good nat behavior and in the cognitive environment of the target readers and their ability of Acceptance should be over thought if we translate "cowardly" into "I the humble man", we may confuse the target readers who lack the same cognitive environment as the Chinese readers do and cause failures in communication to make a successful communication, here we had better make clear the communicative intention of the author and translate "cowardly" simply into the "I".

\section{Optimal relevance}

According to Sperber \& Wilson, ${ }^{13,14}$ the human beings have the nature to notice, state, process and interpret the information that is relevant to them. In the process of communication, the communicators will make clear that his/her information has some relevance to the audience in addition to informing the audience of something. Therefore, the audience may infer the addresser's intention and interpret the utterance correctly with the presumption of such relevance. Sperber \& Wilson ${ }^{14}$ define relevance as follows:

Extent 1: an assumption is relevant in a context to the extent that its contextual effects on this context are large.

Extent 2: an assumption is relevant in a context to the extent that the effort required to process it in this context is small. Sperber \& Wilson. $^{14}$

This definition shows that there are mainly two factors that relevance is dependent on: contextual effects and processing effort. ${ }^{15}$ contextual effects which have been mentioned in section 4.1.1 are important factors in evaluating the degrees of relevance, which we can conclude from the words: "having contextual effects is a necessary condition for relevance, and that other things being equal, the greater the contextual effects, the greater the relevance." (ibid.: 119) the processing effort is the second important factor to be taken into consideration in evaluating degrees of relevance, which can be inferred from the processing effort is a negative factor: other things being equal, the greater the processing effort, the lower the relevance" (ibid.: 124).

In RT, both the addresser and the audience attempt to pursue optimal relevance. "Every act of ostensive communication communicates a presumption of its own optimal relevance." 14 it is believed to be the principle of relevance. The central claim of RT is that human communication crucially creates all expectation of optimal relevance. ${ }^{15}$ that is to say, it is an expectation on the part of the hearer that his attempt at interpretation will yield adequate contextual effects at the minimal processing cost. The audience always focuses on the most accessible information first when searching for the optimal relevance, for it costs less processing effort. However, sometimes it is hard for the audience to Produce an adequate he/she contextual effect, so will have to make more effort to find out the real intention of the communicator. It will be worthwhile as long as the processing effort can be balanced by the benefits of obtaining contextual effects. In addition, relevance is a comparative notion, and addressing in utterances varies according to the degree of relevance they achieve in some context.

\section{Relevance theory in translation studies}

In the following part, we will make a review of the studies made by scholars at home and abroad on translation from the perspective of RT

\section{Studies in western countries}

Ever since the RT came into being, it has exerted a big influence on many subjects. Gutt ${ }^{15}$ however, it is a student of Sperber \& Wilson, ${ }^{14}$ who applies this theory to the field of nat whose ideas are clearly interpreted in the work of translation and relevance: cognition and context (Gutt). ${ }^{15}$ Gutt $^{15}$ first explains some of the contradictions in translation and concludes that RT has a great explanatory power over translation. He also claims that faithfulness in translation is to communicate an intended interpretation of the source text through adequate contextual effects achieved without unnecessary processing efforts. He boldly claims that "the principles of translation of the rules and guidelines are applications of the principles of relevance". (Ibid. 
198) the task of the translator is to expose the intention of the original author and provide the optimal relevance through the contextual effects. Therefore, the target readers can understand the original text without too much processing effort. Naturally, Gutt's ${ }^{15}$ point of view have attracted different comments, some of which criticize his unscientific way of study. However, we have still got many inspirations from his thoughts.

\section{Studies in China}

The Chinese scholars have also noticed the explanatory power of the RT in translation. It is Lin Kenan ${ }^{16}$ (the author of the pragmatics: A focus in translation studies, 1996) who first introduced the relevancetheory study of translation into china and later on, Zhao Yanchun ${ }^{17}$ (the author of a theoretical research on pragmatics and cognition, 2001) made a research on translation from the perspective of RT. In his book of a reductionist approach to translatology, Lin Kenan ${ }^{16}$ mainly talks about some of the contradictions in translation studies, especially the controversial concept of untranslatability. He explains to what extent equivalence can be achieved. These two phenomena are invalidated through applying Sperber's and gutt's theory. He also explains the phenomenon of cultural default in translation; he defines translation as "an act of ostensive-inferential intralingual or interlingual interpretation of a source text." (ibid. 426) therefore, in his opinion, the default information does not form a mutual cognitive environment for the communicators and it can be filtered in the process of translation, other scholars like He Ziran ${ }^{18}$ also give positive opinions on the application of RT in translation. In chapter four, we will discuss if RT can explain the cultural default in translation.

\section{A relevance-theory approach to translation}

The various translation theories proposed by different scholars can be classified into descriptive or prescriptive approaches. RT goes beyond the bounds of this and views interlingual communication as a single process. Ostensive-inferential however, translation consists of a double ostensive-inferential process that is to say, translation has three parts: the original author, the translator and the target reader during the process of translation the translator should first use his/her cognitive environment to infer the original author's intention and to find the optimal relevance. The cognitive context of the target text is unknown before the text is published and the translator should make the context of the target text raise the reader's interest. Therefore, the translator should know his or her potential readers with proper cognitive context and let the translator and the readers share the optimal relevance.

Next we should have a look at the principle of translation In section 4.2.1, we have talked about the principle of relevance, which is to find the optimal relevance during the process of translation. In terms of judging to what extent the target text resembles the source text, the principle of relevance plays important part relevance depends on two elements: processing effort and contextual effects. The key point of communication depends on whether the speaker and the audiences can find the optimal relevance, and the optimal relevance is a dynamic concept because it depends on the cognitive context provided by the translator and the target readers' cognitive effort. If the translator gives the target text readers the explanation in accordance with the principle of relevance, the target text and the source text will have resemblance and that is also the principle of translation.

\section{Cultural default and equivalence \\ Cultural default from the perspective of relevance theory}

Cultural default, though a natural result and common phenomenon in communication, often gives rise to failure in cross-cultural communication. In this section, the phenomenon of cultural default will be discussed from the perspective of RT.

\section{The definition of cultural default}

Cultural default is defined as the absence of relevant cultural background knowledge shared by the author and his/her intended readers in their communication through texts. Cultural default is a cognitive matter in human communication in nature and RT, with communication and cognition as its core, can explain cultural default.

\section{Cultural default from the perspective of relevance theory}

As the pragmatic theory RT is to find the inner relationship between different objects through cognitive environments. Speaking, generally people who live in the same sociocultural environment usually have shared cultural background knowledge, and this mutual cultural knowledge is presupposed in their communication. Cultural background knowledge forms an intrinsic part of an individual's cognitive environment and exists in the form of schemas encyclopedic assumption which can be completed into full-fledged assumptions on the basis of certain contextual information.

Wang Bin criticizes the RT because he thinks it fails to explain cultural default. However, Zhao Yanchun ${ }^{19}$ explains that RT has enough explanatory power over cultural default on the basis of the following three statements: Translation allows the existence of cultural default and what's more, translation cannot avoid cultural default. And all cognitive and communicative process of human beings cannot avoid the default. RT is also based on cognition and communication. Therefore, translation and RT theory are mutually compatible. Here is an example:

He is something like Li Kui, and he will take out his knife to fight with soemone without saying a few words.

$\mathrm{He}$ is really a Li Kui: any words can bring him into rage. ${ }^{19}$

The culture, in Chinese Li Kui" is a character in the famous classic work outlaws of the marsh, who is well-known for his bad temper. He usually pulls out his two axes before fighting. He is familiar to most of the Chinese and has become a fixed figure to describe the people who have the same kind of character. However, the English readers may not have the same kind of cognitive environment, so the cultural background information contained here is seemingly omitted in this utterance. however, by the hint of the following contextual information any words can bring him into rage", it is easy for the Chinese addresser to make clear his idea to the English readers That he is a man of bad temper, in this way, the default can be compensated to some extent.

When an utterance is formed, the unnecessary information is usually omitted in the process of communication. People tend to focus on the most relevant information which can help them form adequate assumptions. The so-called optimal relevance is in fact the 
relevance that has filtered out the unnecessary trivial information. When processing the information, people tend to get the maximal contextual effect with minimal processing efforts and which part of the information should be adopted depends on the predilection and the attention of the hearer. Dealing with cultural default in translation is also based on it. However, dealing with cultural default in translation is more complex than in the common communication, because cultural default in translation originates from the cultural idiosyncrasy but cultural idiosyncrasy is a sort of relative concept, because we all own the same world and have the same kind of feelings which we express by different language codes. According to the nature of language, we can say that even languages created in different times cannot be translated. However, according to the nature of that it is workable because the core of translation is to communicate Zhao. ${ }^{19}$

\section{Equivalence from the perspective of relevance theory}

Language systems are different. Therefore, the understanding of certain language codes by different people is also different. In this sense, it seems that "equivalence" is impossible. However, communication can be realized among human beings because people's intentions can be expressed. So we can say that the "equivalence" really exists. This forms a contradiction in translation. Because of this nature of "equivalence", we must try to find the "equivalence" on condition that there is no absolute equivalence between languages.

Language and information depend on each other. Language is the tool of conveying information. Information and its conveyance have formed an integral part when we see a signifier, we call infer what it is signified. However, although we may find that certain words have their equivalents in another language (when the language environment changes, the connotation of the words will change too. it is also the reason why grice introduces the inferential model and why Sperber \& Wilson ${ }^{14}$ develop the inferential model. The inferential model wants to expose the original author's intention, namely, to find the optimal relevance between the utterances and the context for the purpose of realizing the communicative effect.

\section{The relativity of equivalence}

If we say that there is no "equivalence" between languages, we make the statement on two elements: one is that there is no static "equivalence" between languages; otherwise, we can do translations through machines. The other is that the statement reflects the nature of language. The process of finding "equivalence" is dynamic and when we are doing translations, we must make a reasonable choice under the cognitive environment.

Rt does not discard equivalence, but prefers to comprehend equivalence in a dynamic way. Equivalence not only refers to the equivalence of language, but also the equivalence of intention. The ideal way of translation is to achieve equivalence both in language and intention, which is the so-called absolute equivalence. However, that idealized state can never be achieved because people in different areas have different ways to express a subject or a phenomenon, so the encoding of the world is different. Meanwhile, the grammatical rules in different languages are also different but it does not mean that translation is impossible because we share the same world and the same feelings. The relevance-theory approach of translation is to achieve equivalence on The basis of successful communication and in this sense, equivalence is a relative concept.

\section{Translation of kinship terms}

In the following part, the translation methods of kinship terms will be discussed, focusing on the cultural default contained in the kinship terms.

\section{Methods to reconstruct the cultural default in translating kinship terms}

Scholars have worked out many translation methods to solve the problem of cultural default in the translation of kinship terms, which are introduced in the following part

\section{The literal translation}

In the Chinese and English kinship systems, there are some terms that correspond to each other. for example, the Chinese kinship terms "grandfather" (Zu Fu, grandfather), 'grandma' (Zu Mu, grandmother), "father" (Fu Qin, father), "Mom" (Mu Qin, mother), "son" (Er Zi, son), "daughter" (N ü Er, daughter), "grandson" (Sun Zi, grandson) and the granddaughter" (Sun n ü, granddaughter) can find their equivalents in the English kinship system. Some scholars call this kind of kinship terms neutral terms which include all the terms addressing relatives for the purpose of Designation, showing little emotional feeling such as respect or modesty. This type of kinship terms in the source language can find their equivalents in the target language. If the intention of the original author to use those kinship terms is to show their original designation alone, we can use a literal translation to deal with them.

\section{Free translation}

However, the kinship terms do not always convey their original designative meanings. Sometimes they are used for special purposes, which make the translation really a complex work. Therefore, we must use special methods to deal with them.

\section{Generalization and specification}

Speaking, generally the English kinship terms, due to the influence of culture, general are more on the contrary, the Chinese kinship terms are more specific and complicated. We have discussed in chapter two that most of the Chinese kinship terms do not show seniority, consanguinity or sex differentiation. Therefore, when we do Chinese-English translations, we prefer to use generalization. When doing English-Chinese translations, we use specification. The most obvious example is the translation of "sister carrie" quoted by Bao Huinan. ${ }^{2}$ someone wants to translate it into the Carrie girl" (Jia Li Gu Niang, literally "carrie girl"), which changes the kinship term into a common appellative word in this way, some of the Information in the source text is lost in the process of translation. How to translate the sister" gives problems to the translators. those who are familiar with America literature know that a younger sister of the author who lived a hard life like the author himself is the prototype of the heroine. So it is proper to translate "sister carrie" into "Sister Carrie" (Jia Li Mei Mei, literally "carrie younger girl"), which gives the Chinese readers more detailed information about the personal identity of the heroine.

\section{Conversion}

There are working kinship terms in English than in Chinese and most of the kinship terms in English are quite vague and general in meaning. Therefore, some of them should be converted from one term to another so that they can correspond to those in the source text and 
at the same time accommodate the norms and conditions of the target for example: language.

Daiyu did not see her before, but her mother told her that Jia Lian, his eldest uncle Jia She's son, had married the niece of Lady Wang, her second eldest uncle's wife, She had been brought up like a boy and received the literary name Xifeng. Daiyu hurried to greet her smilingly with "cousin".

Though Tai-Yu had never met her, she knew from her mother that Chia Lien, the son of her first uncle Chian Sheh, had married the niece of Lady Wang, her second uncle's wife. She had been educated like a boy and given the school name Hsi-feng. Tai-yu lost no time in greeting her with a smile as "cousin". (A dream of the red chamber by the Cao Xueqin, ${ }^{10}$ trans. Yang Xianyi \& Gladys Yang $\left.{ }^{10}\right)$.

This example shows the situation of Tai-Yu first meeting his Feng who was introduced by the author as the wife of Chia Lien. So Tai-Yu should greet her as a "Sister" sister-in-law) (Sao, which means "" however, sister-in-law. We all know that the family relationship in the dream of the red chamber by Cao Xueqin ${ }^{10}$ is quite complex. And according to the patrilineal relationship, Tai-Yu and Chia Lien actually belong to two families and their relationship is equal to that indicated by the "cousin" in English and as the wife of Chia Lien, his Feng and Tai-Yu are also cousins. So "cousin" can give the target readers a clearer understanding of the relationship between hsifeng and tai-yu than the sister-in-law".

\section{Amplification and omission}

Amplification refers to the technique of retaining the kinship terms in the source language and meanwhile adding a few words which can bridge the cultural gap to help the target readers understand the pragmatic meaning. When the target readers have difficulties in accurately understanding the figurative or associative meanings of the kinship terms, this kind of method is really helpful. For example:

Mrs Sun, your respected sister, missed you very much when she was around.

Your honorable sister Mrs. Sun missed you very much during her lifetime.

(A practical course book on translation, Feng Qinhua ${ }^{20}$ )

In this example, Deng Yingchao ${ }^{19}$ (Deng Ying Chao, the wife of the former premier Zhou Enlai, uses a polite and respectful tone which is also reflected in the kinship terms. stylistically, "Sister" (Ling Jie, your elder sister) is a polite form of address, and the polite tone in this letter is quite important because it is of political use. If we simply translate it into "sister", some of the pragmatic meanings will be lost. So we had better add "honorable" before "sister" to show the original tone. Omission refers to the technique of deleting unnecessary parts of the source text in the target text here is another example:

Every time when a guest comes from a far and speaks of the madam's daily life, a feeling of nostalgia arises in their minds. They have heard that the madam is in good health, and they are very happy.

Every time a friend comes from afar and mentions your daily life I cannot help recalling the past. It is a great comfort to me when I hear that you are in good health. (A practical course book on translation, Feng Qinhua ${ }^{20}$ )
In this example, the "Lady" (Fu Ren, madam) is also a polite form of address. But why do we use omission here? Deng Ying Chao uses "wife" to address song meiling (Soong Mei-ling, the wife of the former guomintang president Chiang Kai-shek), the person she is speaking to. Literally, "wife" means "your ladyship" here. However, if we translate it into "your ladyship", we may give the target readers an impression that the two persons are not on equal status because of the cultural difference. To avoid failures in communication, it is better to omit the polite tone which is of less importance.

\section{Paraphrase}

If the methods mentioned above fail to make the source text clear, we can use paraphrases to give more detailed information about what we want to say. Please look at the following example:

My dear brothers, please look at me! I show my respect for all of you. We are brothers and thus should not hurt each other!

Brothers, look at me, I am praying my respects to you, we are all one big family-don't do anything to our friendship. (Teahouse Lao She, ${ }^{20}$ trans. Huo $\mathrm{Hua}^{20}$ )

In this sentence the initial purpose of the speaker to use "brothers" (Di Xiong, younger brother and elder brother) is to emphasize the intimate relationship between the speaker and the hearers that is to say, the socialized function of this kinship term is more obvious than its original designation. If "are your own brothers" (Dou Shi Zi Ji Di Xiong, all are one's own brothers) is changed into "are brothers" (Dou Shi Zi Ji Ren, all are one's own persons), it makes no difference to the Chinese readers because the original designative meaning of "brothers" is not important. Therefore, it is proper to paraphrase it into "we are all one big family", which clearly shows the intention of the speaker.

\section{Reconstructing the cultural default from the perspective of relevance theory}

According to RT, every act of ostensive communication communicates the presumption of its own optimal relevance. The translator should find all the possible information to convey the original meaning of the source text to help the target readers to form a right assumption and filter the unnecessary trivial information which gives little help to the target readers' right understanding. Here I quote an example to show how to find the optimal relevance in translating:

Hong Yu, a sister said: We asked grandma grandmother well. The original is my second secretary at home, while late for two days only. Please feel free to grandma. The five grandma, grandma, we also have to look at the five grandma? The grandmother of five children before the game, the maternal grandmother with a letter, and asked his grandmother well, and here's your grandma addressing two pills delay, the identification of God VP Dan, and if so, agrandmother who game, the only addition in our grandmother here. The children have to go to Shun Road to the side of his milk with milk."

She said, "Our lady sends her compliments to her ladyship. Our second master is away from home now, so her ladyship shouldn ' $t$ worry over a couple of days' delay. When the fifth mistess is better, our lady will come with her to see her ladyship. The fifth mistress sent a servant the other day to report that our lady's sister -in-law would oblige her with two longevity pills. If her ladyship has any to, please 
send them to our lady, and the next person to go that way will deliver him to her sister-in-law.

(A dream of the red chamber by the Cao Xueqin, ${ }^{10}$ trans. Yang Xianyi \& Gladys Yang ${ }^{10}$ ).

In this passage, the term "nai nai (grandma, grandmother)' is used fourteen times and none of them shows the meaning of "grandmother". The translator specifies the meaning of all these terms into the lady (ship), mistress, her, sister-in-law". By using this kind of paraphrase, the intention of the author is well expressed, and the status and the identity of those women are clearly shown. However, part of the stylistic character of the original text has been lost. The original author intends to use repetition to show that the speaker has a good skill of expression. Because of the difference in language structures, the repetition is hard to express in English if we want to maintain the original meaning of the text. In this case, we must make a choice according to the contextual effect and the optimal relevance. Obviously, to make clear the identity of the figures is more important than to show the same kind of figure of speech. let us imagine that, if we all use the nainai" here like what Lin Yu Tang did in his moment in Peking, the target readers who lack the same cognitive environment as the Chinese will be confused by the relationship that the speaker describes. le us discuss in detail how RT works in the translation of kinship terms.

\section{The exploration of the original intention}

As has been mentioned in section 4.1.3, the intention of the original author intention involves both informative and communicative Gutt, ${ }^{15}$ intention. According to the intended interpretation of an utterance consists of its explicatures and/or implicatures. thus to say that a translation should communicate the same interpretation as that intended in the original means that it should convey to the receptors all and only those explicatures and implicatures that the original was intended to convey." (2004:99) so a translator should first of all detect the intention of the writer. let us see the following group of examples:

\section{Example I}

My man, you know your hair is our Chinese treasure and gem, and too many people have suffered a lot in this respect throughout the ages!

You know, my friend, in china hair is our pride and our bane. How many people since ancient times have suffered because of it, all to no purpose?

(Call to arms by Lu Xun, ${ }^{22}$ trans. by Yang Xianyi \& Gladys Yang ${ }^{22}$.

In the original text, the speaker who is described as an odd and inexplicable person. The author and this speaker are not brothers and they are even not familiar with each other. Here "man" (Lao Xiong, old guy) is just used as a common appellative word to draw the hearers' attention. In my opinion, there are two kinds of translation that can be used here considering the speaker's intention. the first one is my friend", which is the closest one to the man." both in the communicative intention and the structure. The second choice is to omit this kinship term since there are actually no specific meanings in it. Both of these two methods are acceptable from the perspective of the target readers. In the Chinese people's cognitive environment, "man" can be used as an appellative term between close friends.
However, the English readers do not have the same kind of cognitive environment. So here, the expression "my brother" does not conform to the habit of the English people. some people may say that there are similar cases in outlaws of the marsh 1998), Wang Lina, but most of them are translated into "brother." as we can the big see, contexts of call to arms and outlaws of the marsh are different. In outlaws of the marsh, the outlaws are sworn brothers and the target readers will not feel strange to see them call each other brothers. However, in call to arms, the only information we know from the author is that the speaker is odd and they are not quite familiar with each other. Their relationship is not close enough to call each other "brother". In this sense, to use "brother" is a little bit abrupt for the target readers.

Cannibalism is my brother! I was eating people's brother!

The eater of human flesh is my elder brother! I am the younger brother of an eater of human flesh.

\section{(Call to arms by Lu Xun, ${ }^{22}$ trans. by Yang Xianyi \& Gladys Yang ${ }^{22}$ )}

Here the method of specification is used because the intention of the author to use "brothers" (Xiong Di, brothers) is just to clarify the relationship and "brothers" in the sentence just means "younger brother", so what the translators need to do is just to express the accurate information.

\section{Example 3}

That was the red officers' habit of saying, "Come on, boys!" Instead of "Go on, boys!"

This is the Red Army Military palace used to say, "Brethren, come with me! "And not "Brethren, forward punch! " (Red star over china by Edgar snow, 2001: 384, trans. Dong Leshan ${ }^{27}$ )

If "boys" is translated into "children" (Hai Zi men and children), the Chinese readers will feel uncomfortable. in this context, "boys" and "Brethren" (Di Xiong men, brothers) have the same pragmatic function. So "Brethren" can be called a successful translation.

\section{Optimal relevance in translating kinship terms}

As has been mentioned in chapter three and chapter four, "the central claim of relevance theory is that human communication crucially creates all expectation of optimal relevance, that is, an expectation on the part of the hearer that his attempt at interpretation will yield adequate contextual effects processing at minimal cost." Gutt $^{15}$ to put more correctly, the expectation created in the hearer is that the communicator believes that the intended interpretation will yield adequate effects without unnecessary processing efforts.

According to Sperber \& Wilson, ${ }^{14}$ the hearer has the right to assume that the first interpretation he arrives at is the interpretation intended by the communicator. For the hearers, when they manage to select the right set of contextual assumptions from what they know, they turn first to highly accessible information.

As to the cultural default in translation, it is the information that does not belong to the mutual cognitive environment and it is the filtered trivial information that gives little influence on the target reader's understanding. That is to say, the default information cannot help the audience to form adequate assumptions. Therefore, the translator must choose what to convey and what not according to the principle of relevance. Let us see the following group of examples. 


\section{Example I}

Besides, as soon as I think of my having met with Sister Xiang Linshao yesterday, I feel not at ease.

Besides, the thought of my meeting with Xiang Lin's wife the previous day was preying on my mind.

(Wandering by Lu Xun, ${ }^{23}$ trans. Yang Xianyi \& Gladys Yang ${ }^{23}$ )

\section{Example 2}

Among the spectators, Sister Bayi was the most kind-hearted person. With her two-year-old posthumous child in her arms, she was looking at the grand scene.

Widow $\mathrm{Ba}$ Yi had the kindest heart of all the onlookers there. Carrying her two-year-old, born after her husband's death, she was watching the fun at Mrs. Sevenpounder's side.

(Call to arms by Lu Xun, ${ }^{22}$ trans. Yang Xianyi \& Gladys Yang ${ }^{22}$ )

\section{Example 3}

Next door lived Sister Shansi, and she became a widow two years ago. She supported herself and her three-year old child by spinning yarn, so she went to bed late.

By midnight there were only two households awake: the house next door where fourth shan's wife for lived. left a widow two years earlier, she had nothing but the-cotton yam she spun to support herself and her three-year-old boy, this is why she also slept late.

(Call to arms by Lu Xun, ${ }^{22}$ trans. Yang Xianyi \& Gladys Yang ${ }^{22}$ )

\section{Example 4}

During my childhood, Sister Yang'er sat in the opposite toufu shop all day long, and she was called "Bean curd Xishi."

When I was a child there was a MRS yang that used to sit nearly all day long in the beancurd shop across the road, and everybody used to call her bean curd beauty.

(Call to arms by Lu Xun, ${ }^{22}$ trans. Yang Xianyi \& Gladys Yang ${ }^{22}$ )

\section{Example 5}

"All of us know that you are serious... You should not commit suicide," said Sister Zouqi on the side.

"Everybody knows you are a good woman," put in Mrs zou from the side. You must think of committing suicide."

\section{(Call to arms by Lu Xun, ${ }^{22}$ trans. Yang Xianyi \& Gladys Yang ${ }^{22}$ )}

Literally, the Chinese kinship term "Sister (A)" (sao, sister-inlaw) designates the wife of one's elder brother and it has a socialized meaning to call married women in the southern Chinese dialect, ${ }^{24-28}$ which is almost equivalent to the usage of "Mrs." however, "Mrs." is used as a courtesy title for a married or a widowed woman before the surname or full name of her husband (see the American heritage dictionary) therefore, the designation of the two words is not quite the same. Here there are five examples and the translator gave three types of translations. In examples 1, 2 and 3, the heroines are miserable women with low status in the society, whose names are not the clear even in the article. Although $\mathrm{Lu} \mathrm{Xun}{ }^{22}$ shows his compassion to the miserable life of the heroines, he also wants to criticize their numbness toward their miserable life. According to the principle of relevance, chooses the words a translator should serve this purpose. So the term "Mrs." cannot let the target readers understand the author's attitude toward those women. Therefore, a description of the identity of those heroines is more proper here and in example 2, the translator uses the "widow" to make clear the situation of the heroine. In the source text, the author has mentioned that she had a two-year-old son born after her husband's death. From this information, the target readers can find that she was a widow. In addition, to use the widow Ba Yi" will give the target readers all impression that her own name is ba yi, which is indeed her husband's name. So I think it is more proper to use the Ba Yi's wife" here.

And in examples 4 and 5, the two women actually did not bear the same miserable fate as the first three. however, both of them are described as selfish persons and gossip mongers. The authors also take a critical attitude toward them. Although their lives are not as miserable as the first three, they do not win the respect from the authors. So we think that, to use the "one' s wife" to translate "Sister" is more proper than to use the "Mrs." 29,30

From the group of examples we can see that, translation is a kind of optimal relevance. The foreignization, domestication and translatability all accord with this principle. We have to learn to find optimal relevance in all acceptable scale" Zhao. ${ }^{19}$

\section{Conclusion}

Every language has its own system of kinship terms to denote the interrelationship between relatives. Because of the difference in culture, Chinese and English bear many differences in their kinship terms as well as their usage, which produces obstacles to the translators. Many studies have been done to solve the problems made by the cultural gap between china and the west. Functionalism is frequently used to explain those phenomena. We try to investigate the translation of kinship terms as a whole system and to find a proper way to solve the problems in translation from the perspective of relevance theory.

According to RT, translation is a kind of communication at its core. The content, context and various implications of all utterances may cause different comprehensions in the hearer, and not all the assumptions available from the potential context are equally accessible at any given point in time. a therefore, translator should find the optimal relevance according to different situations. The main problem we may meet in the translation of kinship terms is cultural default. The previous studies have provided such methods to solve this problem as generalization, specialization, conversion, amplification, omission and paraphrase. These methods are workable to some extent in a local level. However, as we can see, translation is a dynamic process and no static method can solve problems in a changing situation. From the perspective of RT, we must take the content, context and the target reader's ability of acceptance into full consideration. Cultural default is mainly considered as the filtered information which only causes difficulties in the process of communication. Therefore, the translator can simply omit it.

It may be argued that it breaks the rule of faithfulness. as has been mentioned in the above chapters, the nature of translation is communication. If a translated version fails to make clear the original meaning to the target reader, how can we call it a translation? 
All in all, as to the question of equivalence, it is a concept in a scale. That is to say, equivalence has degrees. There is no absolute equivalence but the convergence of meaning. Equivalence guided by an optimal relevance means to find the closest one in that scale. Therefore, from the analyzes we can see that RT has a great explanatory power over the translation of kinship terms.

However, since RT investigates the translation in a macroscopically level (it is hard for translators to find a concrete standard to evaluate the translation which may cause many arguments in the quality of a translation work. anyway, it provides a new approach to the translation of kinship terms and we believe that further studies in this field will yield more excellent findings in the future.

\section{Acknowledgement}

The present study is part of the research project entitled "Research on the translation and dissemination of about us in the West" "'Songs of the South" Translation and Communication Research in the Western World") which was funded by the Hubei Provincial Department of Education, P. R. China (grant no. 17ZD016).

\section{Conflict of interest}

None.

\section{References}

1. Fasold R. The Sociolinguistics of Language. Foreign Language Teaching and Research Press. 2000. 389 p.

2. Bao HN. Cultural Context and Linguistic Translation. China Standards Press. 2001. 350 p.

3. Wilson D. Meaning and Relevance. Press: Cambridge, Cambridge University UK; 2004; 306:232-233.

4. Li JY. On Translation of Terms of Address from the Perspective of Cultural Differences. Phd Dissertation. Chengddu: Sichuan Normal University; 2007.

5. Zhang AQ. Mode of Thinking and Cultural Differences. Overseas, English. 2007;6:81-86.

6. Zhai Y. An Exploration into Cultural Translation Strategies. Master's Thesis. Taiyuan: Taiyuan University of Technology.

7. Wu, XM. A Socio-Pragmatic Contrastive Analysis of terms of Address in Thunderstorm and Major Barbara. Master's Degree. Shanghai: Shanghai Maritime University; 2006.

8. Morgan LH. System of Consanguinity and Affinity of the Human Institution: Family. Smithsonian Washington, USA; $1971.604 \mathrm{p}$.

9. Ba Jin, Yang XY, Press G Yang. Foreign Languages. 2007. $562 \mathrm{p}$.

10. Cao XQ. A Dream of Red Mansions. In: Yang X, Yang G, editors. Foreign Languages. Press, Beijing, China, 2007. 630 p.

11. Dickens C, Martin Chuzzlewit. In: Ye WZ, editors. Shangahi Translation Press, Shanghai, China, 1983. 368 p.
12. He ZR, Ran YP. Pragmatics and Cognition: Theory. Relevance to Research on Foreign Language Teaching and Research Press. 382:232-233.

13. Sperber D, Wilson D. Relevance: Communication and Cognition. Wiley-Blackwell: Hoboken, USA; 1986;338:232 233.

14. Sperber D, Wilson D. Relevance Theory. Foreign Language Teaching and Research. 2001. 82 p.

15. Gutt, E. Translation and Relevance. Shanghai Foreign Language Education Press: Shanghai, China;, 2004. 79 p.

16. Lin KN. Pragmatics: a Focus in Translation Studies. Fujian Foreign Languages. 1996;4:35-39.

17. Zhao YC. A Theoretical Research on Pragmatics and Cognition. Nankai University, Tianjin, China; 2001. 402 p.

18. He ZR. Inference and Reference of Pragmatic Implications. Fujian Foreign Languages. 2001;4:5-10.

19. Zhao YC. A Reductionist Approach to Translatology of Shanghai. Foreign Language Education Press: Shanghai, China; 2005; 368 pp.

20. Feng QH. A Practical Course book of Translation. Shanghai Foreign Language Education Press, Shanghai, China; 2008; $791 \mathrm{pp}$.

21. Lao S. Teahouse. In: Huo H. Foreign Languages Press. 2004; $92 \mathrm{pp}$.

22. Lu, Xun. Call to Arms. In: Yang XY, Yang G, editors. Tianjin Peopless Publishing. House: China; 2002;200:232-233.

23. Lu, Xun. Wandering. In: Yang XY, Yang G, editors. Foreign Languages Press. China; 1981;261:232-233.

24. Kroeber AL. The Valley Nisenan: University of California. Los Press. USA; 1929; 44 pp.

25. Liang ZJ. The Collection of Kinship Terms. Zhonghua Book Company: Beijing, China; 1992;559:232-233.

26. Ma J, Chang W. Research on Chinese Address Terms and Translation. Foreign Language and Translation. 1997;2:115119.

27. Snow E. Red Star over China. Dong LS. Foreign Language Teaching and Research Press. 2001. 767 p.

28. Wang B. Limits of the Explanatory Power of Relevance Theory for Translation. Chinese Translators Journal. 2000;3:36-40.

29. Wang LN. Shui Hu Zhuan (outlaws of the Marsh) In Foreign Countries (Part 1). Journal of Tianjin Foreign Studies University; 1998. p. 63-71.

30. Wang LN. Shui Hu Zhuan (Outlaws of the Marsh) In Foreign Countries (Part 2). Journal of Tianjin Foreign Studies University. 1998;4:77-88. 